\title{
Un Dios con entrañas de misericordia que escucha el clamor de su pueblo
}

\author{
Rafael de Sivatte, \\ Centro de Reflexión Teológica, \\ San Salvador.
}

\section{Introducción}

En otras ocasiones he escrito sobre temas fundamentales del Antiguo Testamento. En este artículo quiero centrarme en un tema que no suele ser tratado con frecuencia o que suele ser abordado de forma espiritualista y alejada del compromiso existencial del creyente. Me refiero al tema de un Dios que tiene entrañas de misericordia y que está siempre atento al clamor del pueblo.

Este tema no es algo coyuntural o esporádico en la Biblia, sino que es central. Y además ese Dios misericordioso llama a su pueblo a un estilo de vida coherente con sus entrañas de misericordia. Podemos hablar, pues, de una contemplación de Dios que llama a la acción.

En otros artículos 1 ya he tratado temas relacionados con éste. Así, por ejemplo, cómo fue el inicio del pueblo de Dios; cómo nació a partir de una reunión de grupos, que se movían por el llamado "creciente fértil" y que vivieron de diferentes maneras experiencias de dominación, opresión y liberación; cómo lo que motivó la unificación de aquellos grupos fue principalmente el descubrimiento de que Dios les había acompañado en su configuración como pueblo y con un nuevo modo de vida humano, justo, solidario, fraternal, de modo que así

1. "Antiguo Testamento y dercchos humanos", Revista Latinoamericana de Teología 27, 1992, pp. 325-344; "Crítica profética a los imperialismos y a la religión nacionalista de Isracl", Revista Latinoamericana de Teología 4, 1985, pp. 95-111; "La Icctura del Antiguo Testamento como un todo", Revista Latinoamericana de Teología 36, 1995 , pp. 235-268; "Monscñor Romcro, los profetas de Isracl y los ídolos: la religión, las potencias extranjeras, las armas, el poder”, Revista Latinoameriana de Teología 41, 1997, pp. 173-192; "Monscñor Romero y los profetas de Isracl: cl ídolo de la riqucza y el Dios de Vida”, Revista Latinoamericana de Teologia 43, 1998, pp. 17-33. 
diesen testimonio de un Dios diferente; cómo en medio de ese pueblo y de su historia siempre surgieron personajes - profetas, sacerdotes, dirigentes, sabios, teólogos- que lo ayudaron a vivir según el nuevo estilo de vida, fundamentado en el Dios de la liberación, y a mantener su relación con Dios y con los demás seres humanos de la manera más auténtica posible, a pesar del pecado siempre presente, de la tentación de manipular a Dios y del egoísmo que lleva a la mentira y a la injusticia.

No voy a repetir esto ahora, sino que me voy a centrar en un aspecto fundamental de la experiencia de aquellos grupos, que llevó a la formación del pueblo de Dios y a un nuevo modo de vivir como pueblo: el descubrimiento gradual y progresivo de un Dios que tiene un estilo propio y que exige un modo de proceder específico. Desarrollaré el tema a través de una lectura diacrónica 2 de los libros del Antiguo Testamento. Dicho de otro modo, veremos cómo, después de su experiencia original de la "liberación", el pueblo de Dios se fue consolidando y muy pronto experimentó crisis y serias dificultades, pero también esperanzas, lo cual lo llevó a profundizar en la presencia de Dios en la historia y a comprometerse a vivir de un modo alternativo.

Para terminar esta introducción, quisiera expresar mi esperanza de que las experiencias de Dios que hizo el pueblo de Israel en medio de su tormentosa historia iluminen las experiencias de nuestros pueblos.

\section{La época gloriosa de la monarquía (950-850 a. C.)}

Comenzamos el análisis en el momento en que el pueblo ya se había organizado monárquicamente con Salomón, más los cien años que siguieron, en los que el país se dividió en dos reinos (Israel al norte y Judá al sur), que vivieron por separado con cierta estabilidad.

La situación fue muy semejante en ambas partes y se dio un gran crecimiento nacional. En Judá, al sur, se vivió una gran euforia durante los reinados de David, Salomón y sus sucesores. Se enorgullecían de haberse constituido como pueblo y de haberse organizado, de poseer diversas instituciones, que les daban identidad (monarquía, templo, montaña de Sión). Creían poder dominar a Dios y manipularlo, porque lo tenían como encerrado en el templo. Dado lo que había hecho en el pasado en su favor, pensaban que Dios estaba obligado a seguirlos bendiciendo.3, a relacionarse con ellos y a ayudarlos porque eran su pueblo.

2. Enticndo por diacrónico un cstudio del tema a lo largo de la historia del pucblo, pero subrayando el nexo que le da unidad.

3. Como ejemplo de csto, cl culto cra comprendido como institución para tener a Dios contento y para forzarlo mágicamente a ponerse del lado de quien le diera culto. 
Esta concepción de Dios llevó frecuentemente a que las personas llegasen a creerse autosuficientes, $-\mathrm{e}$ incluso a creerse dioses con respecto a los demás —4, lo cual tuvo las repercusiones sociales que eran de esperarse: la acumulación de tierras a causa de la ambición, la violencia asesina cuando era necesario, el empobrecimiento y la esclavitud del prójimo para conseguir la propia libertad y enriquecimiento. Se llegó así a una visión antropocéntrica, en el peor sentido de la palabra, ya que el endiosamiento propio con respecto a los demás llevó a ignorar que Dios se había manifestado precisamente para que unos no se hiciesen dioses de otros, sino que todos y todas fuesen iguales, en la familia de Dios. La realidad que comenzaba a surgir en Jerusalén (el templo, el culto, la euforia nacional, el rey Salomón, organizador de un nuevo Estado y respetado por todas las naciones) era, pues, totalmente contraria a la experiencia original del pueblo5.

En el norte, en Israel, ocurrió algo parecido, aunque con algunas diferencias. En aquella época de crecimiento nacional, en Israel se fue desarrollando una visión religiosa impregnada del baalismo cananeo. Este baalismo fue penetrando cada vez más la vida del pueblo: un cierto autoritarismo del poder (en cuanto que Baal justifica la autoridad del poder, lo hace divino y absoluto), los cultos de la fertilidad, con la intención de que Dios se pusiese de su lado (téngase en cuenta que Israel era un país mayoritariamente agrícola, y por tanto, era muy importante conseguir de la divinidad que los campos y los animales fuesen fecundos), una grave manipulación de la salvación, creyendo poder comprarla a Dios. Nada de esto tenía que ver con el Dios misericordioso y gratuito, con quien el pueblo había vivido desde el principio y que no debía ser olvidado nunca, ya que se encontraba en el origen de su misma existencia.

En conclusión, la visión religiosa de los dos reinos, Judá e Israel, se fue deteriorando. Se produjo una imagen falseada de Dios (contraria a la experiencia del Dios de la misericordia, de la gratuidad, de la igualdad y de la libertad) con graves repercusiones sociales: convirtió a los pobres en desprotegidos y en auténticas víctimas de la sociedad.

Pero en medio de esta situación surgieron también creyentes que cuestionaron e interpelaron la fe del pueblo. Por todos los medios, intentaron conservar aquella experiencia primera, "revolucionaria": el descubrimiento de un Dios que no se parecía en nada a los dioses manipulables con los que se podía comerciar. Para

4. No se trataba sólo, por lo tanto, de posecr la imagen de un Dios manipulable, sino de que el ser humano ocupaba el lugar de Dios y se convertía en el auténtico centro de toda la realidad, con frecuencia dominador despótico de los demás.

5. Aquel pueblo había nacido de una experiencia en la que Dios lo había llamado a vivir fraternalmente, en la que Dios se le había hecho presente en la historia de un modo gratuito, en la que Dios lo había acompañado. Y, sin embargo, en tiempos de David, de Salomón y de sus sucesorcs, aquella experiencia comenzaba a scr ocultada y ahogada. 
hacerlo, aprovecharon algunos relatos e historias antiguas y expusieron con toda claridad el estilo de ese Dios que había hecho nacer al pueblo, y el estilo de vida al que eran llamados por él. Así, escribieron los libros del Génesis y del Exodo.

Veamos a continuación algunos textos que confirman lo anterior. En ellos se corrige lo que de malo estaba sucediendo en la sociedad y se recuerda, de diferentes maneras, el estilo de Dios. Los textos están esparcidos en diferentes partes del Génesis.

En el contexto de la historia de Sodoma y Gomorra, por ejemplo, donde se habla de la gran corrupción de aquellas dos ciudades ${ }^{6}$-corrupción que había llevado a Dios a tomar la decisión de destruirlas-, se menciona también cómo Abraham intercedió ante Yahveh para que perdonara a ambas ciudades, basado en la justicia de unos pocos de sus habitantes. Según los creyentes que recogen esta historia en tiempo de Salomón, "Yahveh respondió: si encontrara en el interior de Sodoma a cincuenta justos, por amor a ellos perdonaría a toda la ciudad" $(G e n 18,26)$. En la situación de confusión que se vivía en Jerusalén, aquellos creyentes querían afirmar sencillamente que Dios, por amor a unos pocos, estaba dispuesto a perdonar a la mayoría. Nos presentan así un aspecto fundamental de Dios: Dios ama tanto a los pocos justos que no tiene en cuenta su número (si son $50,40,20,10$ ó 5) para perdonar a todos. Lo que mueve la acción de Dios no es el número o los méritos de los justos, sino el corazón y el amor de Dios. Recordar esto era muy importante y debió ser chocante en aquella corte de Jerusalén, que continuamente pretendía comerciar con Dios. Frente a ello, el texto subraya la gratuidad de un Dios que está siempre dispuesto a perdonar por amor.

En el mismo contexto, se describe la decisión de Dios de salvar a Lot y la razón es la misma: la compasión que siente hacia él7. El texto de Génesis 19, 16 dice así: "Viendo que Lot se estaba demorando demasiado, ya que Yahveh se había compadecido de él, sus mensajeros le agarraron de la mano, junto con su esposa y sus dos hijas, y les sacaron de la ciudad". Lo impresionante de este texto es que Dios quiere salvar a Lot, sencillamente, porque está sufriendo y la razón para compadecerse y salvarlo es la solidaridad y la comunión entre ambos?.

6. Téngase en cuenta que posiblemente el texto no está pensando sólo cn aquellas dos ciudades corruptas, sino que tiene presente a las capitales de Judá e Israel, interpclándolas con aquella historia del pasado.

7. Es bueno acostumbrarse a este tipo de lenguaje. El Antiguo Testamento no presenta sólo a un Dios de venganza, sino a un Dios apasionado, que sc compadece de su pueblo. Hay que tener en cuenta además que el término compadecerse no significa sentir lástima, sino padecer con quicn sufre, hacerse tan solidario que se sufre con él.

8. Es este otro ejemplo, aunque aislado, donde aparecen las palabras amor, compasión, entrañas de misericordia. 
Génesis 26, 24, es uno de los pocos textos que tiene a Isaac como protagonista9. Se dice que a Isaac lo acompaña la desgracia y en este personaje se sintetizan y simbolizan las dificultades de aquellos antiguos semisedentarios, quienes tuvieron que luchar para sedentarizarse y que tuvieron grandes problemas con los filisteos para poder hacerlo. De hecho, siempre que conseguían pequeños logros (por ejemplo, al descubrir pozos de agua en la zona semidesértica), los filisteos los atacaban y les ponían fuertes obstáculos. Frente a ello, ¿cuál era la actitud de Yahveh? Dice el texto: "Aquella misma noche el Señor se apareció a Isaac y le dijo: yo soy el Dios de tu padre Abraham. No tengas miedo, ya que yo estoy contigo. Te bendeciré y haré crecer el número de tus descendientes por amor de mi siervo Abraham". De nuevo, los creyentes del tiempo de Salomón proclaman así que Dios se ha comprometido con Isaac, no porque fuese persona importante o extraordinaria o llena de méritos, sino que la compasión ha sido motivada por el amor que tenía a su padre Abraham10. El texto termina afirmando que Dios logró que los filisteos se compadeciesen de Isaac, fuesen más razonables y reconociesen al pequeño Isaac el derecho a tener un pedazo de tierra y agua.

Un texto parecido, ahora en el contexto literario de la historia de José en Egipto, vuelve a recordar que Yahveh mostró su misericordia hacia él, cambiando el corazón del jefe de la prisión, quien mejoró su situación en aquel lugar. Génesis 39, 21 dice así: "José, pues, estaba en la cárcel, pero Yahveh estaba con él; se mostró bondadoso con José e hizo que se ganase la estimación del jefe de la prisión". Lo importante de este texto es que Dios gratuitamente tuvo misericordia de José y por ello lo salvó. Y la misericordia de Dios produjo el cambio del corazón del jefe de la cárcel. De nuevo aparece en este texto la imagen de un Dios misericordioso frente a la falsa imagen que se estaba creando en la corte de Salomón de un Dios con el que se puede comerciar.

En esta época de la monarquía, cuando continuamente el pueblo corrió el peligro de caer en la idolatría —una idolatría con un nombre no demasiado definido (vanidad, dinero, poder) - aparece el texto de Exodo 20, 4-6. Con él se da inicio al decálogo, las "diez palabras"11, en donde se exige la monolatría. Ante el peligro de pensar que se puede manipular a Dios, que se le puede tratar como a una imagen humana y según el propio gusto, el texto enfatiza la visión tradicional de Dios, el Dios de la experiencia histórica. Dice así:

9. Normalmente, el libro del Génesis tiene como protagonistas a Abraham y Jacob. Cuando sc menciona a Isaac, sc lo menciona en relación con su padre Abraham o con su hijo Jacob.

10. Una vez más nos cncontramos con que cl amor de Dios es cl que produce una acción salvadora, en este caso en relación a Isaac.

11. Es el inicio del Código de la Alianza, que es una especie de Constitución del pueblo de Israel. 
No te harás escultura ni imagen alguna ni de lo que hay arriba en los cielos, ni de lo que hay abajo en la tierra, ni de lo que hay en las aguas debajo de la tierra. No te postrarás ante ellas ni les darás culto, porque yo Yahveh, tu Dios, soy un Dios celoso, que castigo la iniquidad de los padres en los hijos hasta la tercera y cuarta generación de los que me odian, y tengo misericordia por millares con los que me aman y guardan mis mandamientos 12 .

Al pueblo que va tras otros dioses, se le pide que vaya tras el único Dios, quien siempre se mantiene fiel. Al pueblo se le exige la monolatría, y la razón que se aduce es que su Dios mantiene el amor por siempre.

En un contexto parecido se afirma que el pueblo corre el peligro de ir tras ídolos que hacen víctimas de los débiles (viudas, marginados, pobres, etc.), tal como ocurría en la corte. Así, el rey Acab de Israel, dejándose llevar por la fe en Baal, cometió grave injusticia contra un pobre, que sólo tenía una pequeña tierra propia, familiar, para robársela; sacrificó al pobre al dios Baal, el dios del poder, del tener, de la ambición. Frente a esto, el Código de la Alianza, Exodo 22, 21 22, afirma con contundencia:

No vejarás a viuda ni a huértano. Si les vejas y claman a mí, no dejaré de oír su clamor y, lleno de indignación, les haré morir a ustedes en la guerra; entonces quedarán viudas sus mujeres y huérfanos sus hijos.

A quienes se han dejado llevar por esta idolatría les sobrevendrá lo peor. Una vez más, aunque en el lenguaje belicoso de la época, Dios escucha siempre el clamor del pueblo maltratado. Esta es la experiencia originaria del pueblo que clamaba bajo la opresión egipcia y encontró acogida en Dios. El texto está también relacionado con las tradiciones de Caín y Abel donde Dios le dice a Caín: "la sangre de tu hermano grita a mi desde la tierra" (Gen 4,10$)$ y yo no puedo dejar de actuar.

La defensa del débil aparece también en Exodo 22, 25-26, que dice:

Si tomas en prenda el manto de tu prójimo, se lo devolverás antes de ponerse el sol13, porque con él se abriga; es el vestido de su cuerpo. ¿Sobre qué va a dormir, si no? Clamará a mí, y yo le oiré, porque soy compasivo.

12. Con estc modo de hablar sc quicre decir "sicmpre".

13. El texto hace referencia a la costumbre de que, cuando un pobre no podía pagar una dcuda contraída, daba al prestamista, como prenda, cl abrigo extcrior. Dado que en Israel la temperatura era bastante moderada, el abrigo no era tan necesario durante el día, pero, al dársclo al acrecdor, expresaba que tenía una deuda con ćl y que sc comprometía a devolvérsela en cuanto pudiera. En este caso, la ley de Israel añadía quc, precisamente porque el pobre no tenía otra prenda de abrigo durante la nochc, era obligación del acreedor el devolverle dicha prenda antes de ponerse el sol para que el pobre se pudicra abrigar en las horas frías de la noche. De otro modo, el pobrc clamaría a Dios, y éste, escuchándole, no tendría más remedio que actuar. 
La actuación de Dios se rige, de nuevo, por la compasión. Dios se enternece al ver al pobre pasando frío. Es misericordioso y no puede tolerar que se adore a los ídolos de la posesión y del tener, olvidando lo que es humano. En este contexto, Exodo 2, 23; 3, 7-9.17 viene a ser un resumen de toda esta primera etapa. En él aparece cómo surgió la experiencia de la presencia de Dios en la historia del pueblo:

Durante este largo período murió el rey de Egipto; los israelitas, gimiendo bajo la servidumbre, clamaron, y su clamor, que brotaba del fondo de su esclavitud, subió a Dios... Dijo Yahveh14: "Bien vista tengo la aflicción de mi pueblo en Egipto, y he escuchado su clamor en presencia de sus opresores; pues ya conozco 15 sus sufrimientos. He bajado para librarle de la mano de los egipcios y para subirle de esta tierra a una tierra buena y espaciosa; a una tierra que mana leche y miel... Así pues, el clamor de los israelitas ha llegado hasta mí y he visto además la opresión con que los egipcios los oprimen... Y he decidido sacarles a ustedes de la tribulación de Egipto... a una tierra que mana leche y miel.

Recopilemos la situación de la primera etapa de la monarquía. En medio de las incoherencias e infidelidades del pueblo (iba detrás de otros dioses, no liberadores ni compasivos, sino que producían víctimas), los creyentes fueron presentando la imagen de Dios que ellos habían experimentado (la del Dios del éxodo), el que no ha podido soportar la opresión del pueblo (la opresión de la viuda, del huérfano), el que llama al pueblo a la fidelidad porque él es fiel.

\section{Excurso: ¿por qué Dios permite el mal?}

Esta visión de un Dios liberador, gratuito y misericordioso parece quedar desmentida por la realidad de un Dios que, en muchas ocasiones, parece dejarse manipular y permitir el mal. ¿Qué decir sobre esto?

En primer lugar, sería importante eliminar de nuestro vocabulario la expresión "Dios permite el mal". Pues, normalmente, de esta forma, no se explica lo que ocurre en realidad. Pero, entonces, ¿qué puede decir la persona religiosa sobre el mal en el mundo? Estamos ante un gran misterio, pero conviene insistir en él. A lo largo de la historia, los seres humanos se preguntan frecuentemente

14. Dios le dicc a Moisés lo que cstá descubricndo. El clamor del pucblo lc ha tocado cl corazón y no puede dejar de actuar. Y añade que por eso ha decidido abajarse hasta los niveles de la humanidad oprimida.

15. Para nosotros "conocer" es una palabra muy intelectual, pero en el Antiguo Testamento tiene un sentido más amplio y fuertc. Quicre decir que Dios vive cn su propia carne aquella misma experiencia de opresión, la conoce a fondo, sabe exactamente lo que ocurre. En Dios, conocer es poscer, cs vivir la rcalidad conocida. Conocer significa estar tan unido a la otra persona que se comparte lo que ella está viviendo. Cuando Yahvch dice, por tanto, "conozco" sus sufrimientos, está diciendo quc cxpcrimenta en su propia carne toda aquella realidad de opresión. 
cómo es posible que, si Dios es bueno, permita el mal. O pueden preguntarse, en lenguaje más fuerte de la misma Biblia, si Dios produce el mal para castigar. Estas expresiones (Dios permite o produce el mal), sin embargo, presuponen la imagen de un Dios que ha producido un mundo ya acabado. Es la imagen de un Dios que crea, él solo, el mundo y le pone unas leyes. Pero no es ésta la imagen bíblica de la creación: Dios pone en marcha un mundo donde existen leyes naturales que tienen sus maneras propias de actuar, pero donde existe también un ser humano, creado libre, que puede hacer de este mundo un paraíso o un infierno (éste es en gran parte el mensaje del libro de Job).

Así, pues, en vez de decir que Dios permite o produce el mal, tendríamos que decir —quizás más cristianamente- que Dios con-padece el mal (padece el mal juntamente con el ser humano). Esta afirmación puede parecer disparatada para quien piensa que Dios es, sin más, todopoderoso, pues ese tal preferiría a un Dios que crease marionetas a las que poder conducir exactamente adónde y cómo él quiere. Pero si a los seres humanos se les quita la libertad, se les quita aquello que los hace auténticamente humanos, capaces de hacer el máximo de bien, pero también con el riesgo de hacer el máximo de mal. Dios, pues, conpadece el mal y la máxima muestra de ese con-padecer es la cruz de Jesús, la locura de la cruz, que dirá san Pablo.

Si nos preguntamos ahora por qué y para qué con-padece Dios, en definitiva, pensamos que no hay respuesta adecuada. Pero quizás podemos decir que lo hace para que veamos en la imagen de aquel crucificado al verdadero Dios, al que se con-padece con la humanidad. Y lo hace también para que veamos el horror de hacer el mal en el mundo. Pudiéramos decir que Dios no quiere forzamos a hacer el bien. Lo que quiere es seducimos, enamorarnos, para que hagamos el bien. En consecuencia, sería una gran manipulación de Dios, mediante la cual se mantendría a la gente en silencio y en calma, utilizar el lenguaje de que "Dios permite o provoca el mal". La Biblia afirma algo muy diferente: Dios no castiga a nadie, sino que quiere el bien para todos y todas. Lo que ocurre es que ha creado un mundo no acabado. Y si la respuesta no satisface del todo, podríamos preguntarnos qué originalidad tendría este mundo acabado, qué capacidad tendríamos los seres humanos para crear un mundo nuevo, para liberar a nuestro mundo del mal, de acuerdo a la voluntad de Dios.

A esto hay que añadir que nunca nos será posible eliminar totalmente el mal, pues por naturaleza, los seres humanos somos contingentes y limitados. No tenemos la capacidad para cambiarlo todo, sólo podemos ir cambiando las cosas progresivamente. Esto es lo que en parte quiere decir el texto de Miqueas 6, 8, cuando, después que Dios ha recriminado al pueblo porque es pecador, éste se pregunta si para agradar a Dios es necesario hacerle sacrificios. Por medio del profeta, Dios responde: 
Ya te han enseñado, ser humano, qué es bueno y qué espera de ti el Señor. Practica la justicia, ama tierna y apasionadamente, y camina poco a poco con tu Dios.

Dios es quien llama a este modo de vivir. Por esta razón, ante el pecado social los grandes creyentes bíblicos lo primero que hacen es volver a hablar de Dios para anunciar, después, las cosas concretas que es necesario hacer. En todo caso, lo fundamental es hacer ver cómo es Dios: un Dios misericordioso, un Dios que escucha el clamor del pueblo, un Dios que se enternece cuando mira al ser humano padeciendo y que lo llama a ser buen samaritano y a acercarse a quien está en necesidad.

\section{La estabilización de la monarquía en Israel y en Judá (750-700 a. C.)}

En el apartado anterior hemos analizado los comienzos de la monarquía (950-850 a. C.). Analizaremos ahora una segunda etapa en que la monarquía ya se había estabilizado. Había pasado ya el primer impacto de la formación del pueblo y la monarquía y se había pasado ya a la cohesión del pueblo en la práctica diaria. Dicho de otra manera, tras el momento de la poesía había llegado el de la prosa, cuando ya el país se halla sedentarizado. Nos encontramos entonces, hacia el año 750 a .C., con el gran movimiento creyente deuteronomista y una serie de profetas: Amós, Oseas, Isaías y Miqueas.

Antes de presentar sus textos conviene preguntarse por qué fue crítico este período tras el establecimiento de la monarquía. ¿Cuál fue la crisis de esa época, una vez que el país ya se había estabilizado y se había pasado de la primera época de gran euforia a una época de sedentarización con la consecuencia de que el pueblo ya tenía sus fronteras, su status y era respetable?

Comencemos por el reino de Israel, en el norte del país. La primera y principal dificultad fue la formación paulatina de una falsa imagen de Dios, producto de la destrucción de su verdadera imagen en el prójimo. El pueblo se sentía tan seguro y autosuficiente que se convirtió en una sociedad muy manipuladora de Dios. Cada vez más se fueron encubriendo los problemas reales de la sociedad tras la imagen de un Dios de los santuarios, del culto... En consecuencia, la mentira y la hipocresía imperaban en la sociedad. El símbolo de esta mentira y de esta situación corrupta fue la época del rey Jeroboam II. El rey, ciertamente, hablaba continuamente de Dios, usaba su nombre en cualquier ocasión, construía santuarios y quería que todos sus súbditos fuesen a ellos. Dirigido por su rey y sus sacerdotes, Israel había llegado al convencimiento de que poseía derechos sobre Dios, de que Dios estaba en la obligación de actuar en su favor y bendecirlo. Este modo de pensar iba, por supuesto, en contra de la experiencia de la iniciativa gratuita de Dios. Esa tergiversación de Dios y de las exigencias del pueblo llevó a convertir las relaciones sociales en terriblemente insolidarias e injustas. 


\subsection{El movimiento deuteronómico}

Surgieron entonces los creyentes deuteronómicos, quienes, para responder a la crisis, además de denunciar la injusticia ("no utilicen balanzas falsas"), presentan sobre todo la auténtica imagen de Dios, que Israel ha vivido en la historia, recuerdan de nuevo quién es Dios para que este recuerdo le permita seguir siendo el liberador.

El primer texto que vamos a analizar es Exodo 13, introducido como una cuña en el libro del mismo nombre, en el cual se hace referencia a la celebración de las fiestas de la pascua, de los ázimos y de los primogénitos, y sobre todo en el que se fundamenta la institución de la pascua. Vuelve así al acontecimiento fundante: "recuerden y celebren la salida de Egipto". En este texto es también muy significativa la unión de la fiesta del rescate de los primogénitos con el acontecimiento del éxodo. Se recalca que Dios no quiere el sacrificio de los primogénitos, contrario a los sacrificios que exigen otros dioses para después bendecir al pueblo16. El texto recuerda cómo es Dios y muestra su diferencia con los baales: el Dios del éxodo es un Dios de vida y éstos son dioses de muerte. Véase el siguiente fragmento:

"Conságrame todo primogénito... Ya sean hombres o animales, míos son todos". Dijo, pues, Moisés al pueblo: "Acuérdense de este día en que salieron de Egipto... pues Yahveh les ha sacado de aquí. Así, cuando Yahveh te haya introducido en la tierra que juró a tus padres que te daría... celebrarás ese rito... consagrarás a Yahveh... todo primer nacido... Rescatarás también todo primogénito de entre tus hijos. Y cuando el día de mañana te pregunte tu hijo: “¿Qué significa esto?”, le dirás: "Con mano fuerte nos sacó Yahveh de Egipto... Por eso sacrifico a Yahveh todo macho que abre el seno materno, y rescato todo primogénito de mis hijos" (Ex 13, 2-15).

Yahveh es definido aquí como el que hace entrar en la tierra prometida, definición que va en contra de los intentos, en tiempo de Jeroboam II, de designar como guerra santa la guerra nacida del egoísmo y de la ambición. Los creyentes del movimiento deuteronómico repetían, más bien, la exhortación a "celebrar que Dios te ha concedido este pequeño pedazo de tierra que ni siquiera es tuyo". El texto, pues, insiste en el Dios de la gratuidad, el único que puede liberar de la arrogancia del ser humano, que cree tener derecho sobre Dios y quiere justificar como "cosas de Dios" sus propias pretensiones. El profeta Amós se lo dirá aún más claro a Jeroboam II más o menos con estas palabras: “¿Por qué dices que es la guerra de Yahveh, cuando en realidad es tu guerra? Esta guerra no sólo no es de Yahveh sino que Yahveh te ha declarado a ti la

16. Este es el contexto del episodio en que Abraham intenta sacrificar a Isaac, narrado en Génesis 22. 
guerra". La imagen de Dios que aquí se ofrece es liberadora; presenta a un Dios que, ante la realidad, pide una actitud basada en la confianza y en la gratuidad.

En muchos otros textos, los predicadores deuteronómicos vuelven a recordar cuál es el Dios de la experiencia de fe. Un primer ejemplo nos lo ofrece Deuteronomio 4, 31: "porque Yahveh tu Dios es un Dios misericordioso: no te abandonará ni te destruirá, y no se olvidará de la alianza que con juramento concluyó con tus padres". Se hace esta afirmación en un momento en que Dios tenía motivos más que suficientes para abandonar a su pueblo17. Israel se mantenía en su infidelidad, había roto el pacto con Dios y no hubiese sido injusto que Dios hubiese roto con su pueblo. Y, sin embargo, Dios no lo abandona, no se siente capaz porque es misericordioso y se mantiene fiel a su alianza. Y al pueblo se le pide coherencia: responder con fidelidad al Dios fiel y misericordioso.

Más adelante, en el contexto de la versión deuteronómica de las diez palabras 18 , y para fundamentar la importancia de su cumplimiento, Dios vuelve a ser descrito como el que mantiene su amor por siempre. Así aparece en Deuteronomio 5, 10: "y tengo misericordia por mil generaciones con los que me aman y guardan mis mandamientos". Con ello Dios está recordando al pueblo que él le será fiel, pero que también Israel lo debe ser.

De nuevo, en Deuteronomio 7, 7-8, ante la infidelidad de Israel se le recuerda que lo que Dios ha hecho con él ha sido motivado por la gratuidad y el amor:

No porque sean el más numeroso de todos los pueblos se ha prendado Yahveh de ustedes y les ha elegido ${ }^{19}$, pues son el menos numeroso de todos

17. En realidad el Dcutcronomio es cl libro que más habla de la contraposición cntrc la fidelidad de Dios y la infidelidad de su pueblo. Está escrito en unos momentos en que csta infidclidad cra rcalidad cotidiana.

18. Es decir, el decálogo o conjunto de principios básicos de conducta que Dios quiere para el scr humano, para que cl pucblo viva de acucrdo con cl pacto que Dios ha hecho con él.

19. El término "clegir", "cscoger", cra muy mal interprctado en ticmpos de Jcroboam II. Era ésta una de sus grandes manipulaciones: "Dios está con nosotros en nuestras guerras". "Si Dios nos ha elcgido quicrc decir que ha optado por nosotros en contra de nuestros enemigos". Pero esta idea de elección no es correcta. "Elegir", en lenguaje del Dcutcronomio y de los profctas, debicra scr más bicn scr traducido por "amar apasionadamente" a alguien; no quiere decir, pues, "amar a uno y dejar de amar a otro". Esta scría una visión muy limitada, basada en nucstras propias limitacioncs, pucs nosotros, cuando ponemos nuestro amor en una persona o realidad, ya no sabemos ponerlo cn otras personas o rcalidades. En cl caso de Dios, "clegir" - tenicndo cn cuenta que ćl tiene un corazón inmenso en el que caben todos y todo- no significa que Dios elige a unos y rechaza a otros, sino que Dios "ama apasionadamentc a su pucblo" cntrc los demás pueblos, a los que, se dice en otros textos, Dios también ha amado. A Jeroboam II, sin cmbargo, no le intercsaba csta comprensión de lo que es clccción, porque cntonces no podía hacer la guerra a los amorreos o a los filisteos. De ahí su manipulación del término "clcgir". 
los pueblos; sino por el amor que les tiene y por guardar el juramento hecho a sus padres, por eso les ha sacado Yahveh con mano fuerte y les ha librado de la casa de servidumbre, del poder de faraón, rey de Egipto.

Así, pues, este texto dice que el pueblo posee la tierra, porque Dios lo quiere, porque es un pueblo pequeño. Así es Dios. Puede imaginarse cómo golpeaba esta concepción de la elección a Jeroboam II y sus cortesanos, quienes no dejaban de repetir: "Dios está obligado con nosotros por lo grande que somos". Y en el verso siguiente se le vuelve a recordar al pueblo que Dios es fiel y es amor, y se le pide: "Reconoce, pues, que el Señor, tu Dios, es realmente Dios. Es el Dios fiel que mantiene su alianza y su amor por mil generaciones a quienes le aman y guardan su voluntad" (Dt 7, 9). Y añadamos otros dos textos:

$\mathrm{Y}$ por haber escuchado estas normas, por haberlas guardado y practicado, Yahveh tu Dios te mantendrá la alianza y el amor que bajo juramento prometió a tus padres (Dt 7,12).

De lo que estaba destinado al exterminio no te quedes nada, para que Yahveh aplaque el ardor de su ira y sea misericordioso contigo, tenga piedad de ti y te multiplique como prometió bajo juramento a tus padres (Dt 13,18).

\subsection{Amós y Oseas}

Los profetas Amós y Oseas llevaron a cabo su actividad en la misma zona y circunstancia que los predicadores deuteronómicos. Por ello insistieron en la importancia que tiene para el ser humano vivir con piedad, misericordia y amor, ya que el estilo de Dios es piedad, misericordia y amor.

\subsubsection{Amós}

Amós no utiliza normalmente el lenguaje del amor para referirse a las relaciones entre Dios y su pueblo, pues es un profeta eminentemente de denuncia. Se encuentra en una situación histórica muy crítica y lo que hace es denunciar y amenazar para intentar que Israel se convierta y revierta la situación.

Sin embargo, Amós tiene algunos textos significativos en esa línea. Al principio de su libro presenta el conjunto más coherente y completo de su mensaje. Para poder denunciar la situación de injusticia de Jeroboam II (los pobres son oprimidos, llevados a los tribunales y condenados gracias a la venalidad de los jueces), comienza su discurso atacando a las naciones vecinas de Israel, lo cual le permite denunciar después, con cierta seguridad personal, la situación de Israel. Entre las denuncias que Amós hace a las naciones vecinas está la de Edom.

Así dice Yahveh: ¡Por tres crímenes de Edom y por cuatro, seré inflexible! Por haber perseguido con espada a su hermano, ahogando toda piedad, por mantener para siempre su cólera y guardar incesante su rencor... $(1,11)$. 
Aunque Edom no es una nación creyente en Yahveh, Amós la denuncia por no cumplir el mandamiento del amor y más tratándose de dos personas o pueblos hermanos 20. El pecado más grave de Edom es, pues, el rencor y el odio al hermano, es la falta de amor y de compasión. El no amar y compadecerse del hermano, tal como lo ha hecho Edom, no sólo va contra Yahveh, sino contra el propio dios de Edom. Así, Amós universaliza el tema del amor y del odio al hermano.

Después de haber denunciado el pecado de las otras naciones, Amós denuncia el de Israel. Este ha escuchado con gusto aquellas denuncias, y por ello no tiene más remedio que escuchar, aunque sea a disgusto, las que Amós le dirige. Amós denuncia con mucho mayor dureza a Israel, a pesar de que sus faltas no son tan graves como las de las naciones. A éstas las había acusado de odio, venganza, destrucción, violencia, asesinatos... Y es claro que ningún dios podía aceptar tales actitudes y acciones. Cuando le llega el turno a Israel, las faltas denunciadas no son tan graves: injusticias en los tribunales, robos legales de las tierras de los empobrecidos, explotaciones y opresiones, intentos por acallar las voces críticas... Sin embargo, Amós da más importancia a estos pecados que a las graves violaciones de las naciones vecinas. Porque Dios se ha volcado total y continuamente en favor de su pueblo y lo ha amado hasta el final, tiene derecho a que el pueblo le responda con fidelidad. En este contexto, el profeta recuerda a Israel los beneficios históricos que Dios le ha hecho:

Yo había destruido al amorreo delante de ellos, que era alto como la altura de los cedros y fuerte como las encinas; yo había destruido su fruto por arriba y sus raíces por abajo. Y yo les hice subir a ustedes del país de Egipto y les llevé por el desierto cuarenta años, para que poseyesen la tierra del amorreo. Yo suscité profetas entre sus hijos, y nazireos entre sus jóvenes. ¿No es así, hijos de Israel?, oráculo de Yahveh (Am 2, 9-11).

Amós transmite el mensaje de que Dios se ha volcado en la historia de Israel con gran amor, esperando que el pueblo respondiera a ese amor. Ha constatado, en cambio, que en Israel hay quienes venden al pobre por un par de sandalias, que lo machacan contra el polvo de la tierra y pasan por encima de su cabeza, que irrespetan a la doméstica, que ponen multas falsas, que no cumplen las leyes de préstamos y deudas... Aparentemente estos pecados no llegan a la gravedad del asesinato, pero, dada la relación que Dios ha ofrecido al pueblo, Amós los considera sumamente graves. Así, pues, aunque Amós no usa, en directo, el lenguaje de la ternura y de la misericordia, sí habla de un Dios que tiene derecho a pedir cuentas por lo mucho que ha dado a su pueblo por amor.

20. Para entender mejor esto, debe tenerse en cuenta que Edom consideraba a Esaú como su antepasado. Amós utiliza, pucs, la tradición de conflicto y de rencor entrc Esaú y Jacob y la ve realizada también en la actitud de Edom respecto a Israel, descendiente de Jacob. 


\subsubsection{Oseas}

Contemporáneo de Amós, y confrontado con la misma infidelidad de Israel, Oseas sí usa el lenguaje del amor en la denuncia y el anuncio21. La razón para ello puede consistir en su propio modo de ser, y, también, en que comienza a sentir la llamada profética y a ejercer como profeta, precisamente, a partir de la experiencia de un amor familiar frustrado.

Un primer texto a tener en cuenta son los tres primeros capítulos del libro de Oseas, donde el profeta relata su frustración familiar, a través de la cual descubre la frustración que Dios debe haber sufrido en relación a Israel: se casa con una joven, tiene tres hijos de ella y todo le sale mal. Así, mediante su propia historia familiar, va explicando la historia de Israel y su infidelidad a Dios, y una forma de captarlo son los actos simbólicos de poner a sus tres hijos nombres que muestran la frustración de Dios. Para el tema que nos ocupa, es conveniente centrarse en el nombre que pone a su segunda hija. El nombre es terrible: no compadecida, y el significado es claro: es el aviso de que tampoco Dios se compadecerá de su pueblo y, en último término, éste dejará de ser el pueblo de Dios. Pero, en realidad, no es así. Continuamente afirma Oseas que Dios no se compadecerá, para decir a continuación que Dios no puede dejar de compadecerse de su pueblo. Es lo mismo que está descubriendo Oseas en sí mismo: tiene la tentación de rechazar y olvidar para siempre a su esposa e hijos, pero descubre que no puede, ya que los sigue amando. Finalmente, Oseas se siente llamado a buscar de nuevo a su familia para rehacer la vida con ella, y anuncia que el nombre de la segunda hija será cambiado por la compadecida, ya que Dios sigue también compadeciéndose de su pueblo y lo quiere hacer realmente suyo. Veamos los impresionantes versos 21 a 25 del capítulo 2:

Yo te desposaré conmigo para siempre; te desposaré conmigo en justicia y en derecho en amor y en compasión, te desposaré conmigo en fidelidad, y tú conocerás a Yahveh. Y sucederá aquel día que yo responderé... los cielos responderán... la tierra responderá... todo responderá positivamente... Yo la sembraré para mí en esta tierra, me compadeceré de "No-compadecida", y diré a "No-mi-pueblo": Tú "Mi pueblo", y él dirá: “iMi Dios!”.

Dios no espera a que el pueblo se convierta para poder llenarlo de amor, sino que Dios llena primero de amor al pueblo con la esperanza de que así se con-

21. Oscas usa este lenguaje a pesar de que podía ser muy mal interpretado, ya que sus vecinos, los cananeos, expresaban toda su religión con las imagen de las relaciones esposo-esposa, incluso de relaciones sexualcs: los baales cananeos y sus ciudades estaban unidos carnalmente y de este modo la tierra era fecundada. Por la ambigüedad de este lenguaje, otros profetas no lo habían querido utilizar. Oseas, en cambio, lo hace con gran realismo, así como con un gran sentido desmitificador, ya que no da pic a que se pueda interpretar la rclación entre Dios y su pucblo como una relación carnal. 
vierta. No le está diciendo "conviértete y, entonces, yo te amaré", sino "yo te amo para que me conozcas y me vuelvas a amar". Lo que Dios quiere es que el pueblo se vuelva a enamorar de él.

Este cambio que el profeta descubre en sí mismo y en el mismo Dios (se han querido vengar de quien ha sido infiel, pero no han podido) no se da en un mundo ideal o fuera de la realidad. El profeta comprende que, como le ocurre a él mismo, cuando Dios vuelve nuevamente a su pueblo para ganárselo, lo hace conociendo su total infidelidad: es un pueblo que hace maldades continuamente. Dios vuelve, por tanto, a un Israel que está totalmente alejado de él. Véanse los siguientes fragmentos de Oseas 4, 1-2;6, 4-6; 8, 9; 9, 10:

Escuchen la palabra de Yahveh, hijos de Israel, que tiene pleito Yahveh con los habitantes de esta tierra, pues no hay ya fidelidad ni amor, ni conocimiento de Dios en esta tierra; sino perjurio y mentira, asesinato y robo, adulterio y violencia, sangre que sucede a sangre... ¿Qué he de hacer contigo, Efraím?... ¡Su amor es como nube mañanera, como rocío matinal que pasa! Por eso les he hecho trizas por los profetas... Porque yo quiero amor, no sacrificio, conocimiento de Dios, más que holocaustos... Porque han subido a Asiria... Efraím se ha comprado amores... Como uvas en desierto encontré yo a Israel... Pero al llegar ellos a Baal-Peor se consagraron a la infamia y se hicieron abominables como el objeto de su amor22.

Esta es la situación real. Dios se pregunta qué tiene que hacer con el pueblo, y él mismo no sabe qué hacer ante un pueblo inconsistente como la nube mañanera o el rocío matinal. Ante tal situación de incertidumbre, el profeta, en nombre de Dios, llama al pueblo a cambiar; ésta es la única solución posible. Esta llamada aparece en textos como el de Oseas 10, 12:

Siembren simiente de justicia, recojan cosecha de amor desbarbechen lo que es barbecho; ya es tiempo de buscar a Yahveh, hasta que venga a lloverles justicia.

Es la llamada a comenzar de nuevo la relación con Dios, a rehacer la experiencia de la liberación de Egipto, poniendo ellos de su parte justicia y amor. Para acabar de convencer al pueblo de la necesidad de cambiar, les recuerda lo que Dios ha hecho y hace con él. En lenguaje impresionante, lleno de carga amorosa, dice Dios en Oseas 11, 1-9:

Cuando Israel era niño, yo le amé, y de Egipto llamé a mi hijo. Cuanto mas los llamaba, más se alejaban de mí; a los Baales sacrificaban, y a los ídolos ofrecían incienso. Yo enseñé a Efraím a caminar, tomándole por los brazos,

22. En su análisis, el profeta parte de la rcalidad más oscura imaginable. En medio de esta situación tan grave, Dios se pregunta qué hacer. Dios mira la realidad de pecado absoluto y recucrda al pucblo que la única salida cs cl amor. 
pero ellos no conocieron que yo cuidaba de ellos. Con cuerdas humanas los atraía, con lazos de amor, y era para ellos como los que alzan a un niño contra su mejilla, me inclinaba hacia él y le daba de comer. Volverá al país de Egipto, y Asur será su rey, porque se han negado a convertirse. Hará estragos la espada en sus ciudades... Mi pueblo tiene querencia a su infidelidad; cuando a lo alto se les llama, ni uno hay que se levante. ¿Qué voy a hacer contigo, Efraím?, ¿te voy a abandonar, Israel?... Mi corazón se me trastorna y a la vez se estremecen mis entrañas. No daré curso... a mi cólera, no volveré a destruir a Efraím, porque soy Dios, no hombre; en medio de ti yo soy el Santo, y no vendré con ira23.

Lo que quiere decir el texto es que a Dios se le conmueve el corazón, cuando piensa que su pueblo puede ser destruido. Este lenguaje de enamoramiento, de amor, es el mensaje central del profeta. Ya había quedado patente en la relación marido-mujer, antes mencionada, relación que pasaba por grandes dificultades, pero en la que, finalmente, el nombre de la hija no-compadecida era cambiado por el de compadecida. Aquí, utilizando un lenguaje de familia (padre-madre-niño), dice lo mismo: a pesar de la infidelidad, de la perversidad y de la corrupción, Dios ahoga todo ello con su amor al pueblo para que éste regrese24. En último término, el profeta vuelve a llamar al pueblo a que vuelva nuevamente a Dios. En 12, 7 se encuentra su última llamada: "Y tú vuelve a tu Dios, ama fielmente, sé justo y espera siempre en tu Dios". Esto es la conversión: ser fiel en el amor y ser justo.

El amor de Dios hace que el pueblo regrese y lo importante es cómo lo hace, después de haber comprendido lo que le quería decir Oseas. Un Dios, que sea tierno como un padre o una madre puede convertir al pueblo y puede hacerlo regresar a él. El texto de Oseas 14, 2-9, con el que acaba el libro, lo dice con toda claridad:

23. Dios habla como un padre o una madre hablan con su hijo, le enseña a caminar, le da de comer. El texto quiere recalcar que a lo largo de la historia, sicmpre ha tratado a su pueblo como lo hacen un padre y una madre con su hijito. Le recuerda su primer acto de amor y ternura al liberarlo del dominio cgipcio y llcvarlo a la ticra, y recuerda también que el pueblo siempre ha huido de Dios. Parece, entonces, que Dios se cnfada y que es indiferente a que Israel vuclva a cacr en manos de Egipto o que sca presa de Asiria. Dios se siente frustrado y parece desear acabar de una vez con su pueblo y dejarlo en manos de sus cnemigos. Pero, en último término, no pucde: su amor y su ternura hacia Israel son demasiado grandes.

24. Estamos ante algo típico de Oseas. El profeta no exige la conversión del pucblo para que Dios le vuelva a mostrar su amor, sino que anuncia el amor de Dios a su pueblo para que éste se convicrta. El amor de Dios es tal que el pueblo casi no ticne más remedio que volverse a él. 
Vuelve, Israel, a Yahveh tu Dios, pues has tropezado por tus culpas. Tomen con ustedes palabras25 y vuelvan a Yahveh. Díganle: "Quita toda culpa, toma lo que es bueno; $y$ en vez de novillos te ofreceremos estas palabras salidas de nuestros labios: Asiria no nos salvará, no montaremos ya a caba$110^{26}$ y no diremos más "Dios nuestro" a la obra de nuestros manos, oh tú, en quien halla compasión el huérfano"27. -Yo sanaré su infidelidad, los amaré graciosamente; pues mi cólera se ha apartado de ellos. Seré como rocío para Israel: él florecerá como el lirio y hundirá sus raíces como el Líbano... Volverán a sentarse a mi sombra...

Esta es la respuesta del profeta Oseas en una situación de euforia, en la que todo parecía marchar bien, pero la realidad era muy otra: mentira, hipocresía, asesinatos. El profeta descubre que la única manera de volver a Dios y serle fiel es recordar y reconocer cómo es Dios y cuál es su estilo, que no es otro que el ser misericordioso y compasivo. Así se cierra el libro de Oseas.

\subsection{Isaías y Miqueas}

Amós y Oseas fueron profetas que hablaron en el norte. Isaías y Miqueas fueron profetas del sur, en circunstancias parecidas a las del norte, pero agudizadas por la fuerte sensación nacional de seguridad y suficiencia que producían tres realidades específicas de Judá: el templo de Jerusalén, la fortaleza en la montaña de Sión y la permanencia de la dinastía davídica. Aunque no se esperaría de los profetas del sur la pasión de los del norte en el hablar, también la tuvieron. Su lenguaje fue más intelectual y aparentemente frío, sobre todo en el caso de Isaías, pero también supieron descubrir y comprender que Dios es un Dios compasivo28.

25. El mismo profeta anima a poner las palabras que convienc que $\mathrm{cl}$ pueblo diga a Dios en este momento de conversión. Las pone a continuación.

26. La primcra confesión que cl pucblo hace es que la alianza idolátrica con Asiria no tiene fuerza divina para salvar; a ésta le sigue la segunda, que tampoco las armas ticnen poder divino para salvar.

27. También afirman que ya no van a confiar en la fuerza divina de ningún tipo de obra o imagen hecha con manos humanas, sino sólo en Yahvch, el que se compadece de los huérfanos. Rechazan, en una palabra, todo camino idolátrico (divinización de Asiria, dc las armas o de todo objcto humano) para afirmar al auténtico Dios, cl que cs misericordioso con los necesitados.

28. El nortc, Isracl, fuc el lugar donde sc concentraron quicnes físicamente habían cstado en Egipto y, por tanto, habían vivido en su propia carne de una manera muy clara y directa que Dios los había amado cuando los había acompañado en aquella salida. Por manera de ser y por tradición, los de Judá eran más fríos. Habían experimentado, tambićn, la libcración del dominio cgipcio y la habían compartido con los del nortc, aunque, en realidad, no la habían vivido tan directamente. 


\subsubsection{Isaías}

Un ejemplo típico de lo que acabamos de decir aparece en el famoso resumen que hace Isaías de su primera actividad, entre los años 740 y 736 . Al comienzo de su actuación, Isaías se encontró con muchos problemas. Existía gran corrupción y tuvo que luchar fuertemente, incluso contra el rey, a pesar de que se mantenía muy cerca de la corte.

En el resumen de su primera actividad, hay una fuerte denuncia, que la formula en la conocida y famosa canción de la viña. En ella se echa de ver perfectamente, a pesar de su apariencia analítica y fría, y a pesar de su tendencia a hablar de Dios en lenguaje un poco lejano29. Cuando hace un sumario de su mensaje esencial, usa el lenguaje de la misericordia. He aquí la canción de la vin̄a (Isaías 5, 1-7), llena de ternura y amor:

Déjenme cantar una canción en nombre de mi amigo. Es la canción de mi amigo y de su amor por su viña. Mi amigo tenía una viña en un terreno muy fértil. Lo cavó y despedregó, y lo plantó de cepa exquisita. Edificó una torre en medio de él, y además excavó en él un lagar30. Y esperó que diese uvas, pero dio agraces. Ahora, pues, habitantes de Jerusalén y hombres de Judá, vengan a juzgar entre mi viña y yo31: ¿qué más se pudo haber hecho a mi viña, que no se lo haya hecho yo? Yo esperaba que diese uvas. ¿Por qué ha dado agraces? Ahora, pues, voy a hacerles saber lo que hago yo a mi viña: le quitaré la cerca, y no será más que maleza para el fuego; derribaré el muro, y pronto será pisoteada. La convertiré en un lugar devastado, no se podará ni se limpiará más, sino que crecerá en ella la zarza y el espino, y a las nubes prohibiré llover sobre ella32. Pues bien, viña de Yahveh Sebaot es la Casa de Israel, y los hombres de Judá son su plantación preferida. Esperaba de ellos honradez, y va creciendo el mal; justicia, y sólo se oye el clamor de los oprimidos.33.

29. A Isaías le gusta hablar de que Dios es cl Santísimo y de que, por tanto, cstá muy alejado de los seres humanos, que somos impuros.

30. Es impresionante el cariño de este amigo hacia su vin̄a. Oscas lo expresaba de otra manera: el padre y la madre dan de comer al niño, le enseñan a caminar. Isaías utiliza otra imagen: la del campesino que ama su campo y hacc todo lo posible para que ćstc dé una gran cosecha.

31. Isaías mantiene al lector en suspenso. Todavía no ha dicho quién cs cl amigo. Aparcce, sin embargo, un "yo" que - ya se puede sospechar- es Dios, el cual pide a Judá que juzgue y se comprometa. Así, Dios podrá haccr comprender, despućs, que la respuesta de la viña al campesino no es peor que la que el mismo Judá ha dado continuamente a Yahveh.

32. Aquí ya se ve con claridad que el dueño de la viña es Dios, ya que sólo él puede prohibir a las nubes que dejen cacr la lluvia sobre la ticra.

33. Es significativo que Isaías, cuando aplica la canción a la realidad de la relación entre Dios y su pueblo, no lleguc hasta cl final. De hecho, al hablar de la viña dicc que scrá destruida totalmente, en cambio no se dice que Dios destruirá a Judá. Isaías es cons- 
Este es un texto típico de Isaías. Ya hemos dicho que su lenguaje habitual para hablar de Dios no es el del amor, pero aquí sí aparece dicho lenguaje: para expresar la relación de Dios con su pueblo de la manera más honda posible, Isaías habla de una relación de amistad, de amor; y habla, además, de un Dios que quiere la misericordia y la fidelidad.

Algo semejante aparece en el capítulo 9, aunque sea de un modo negativo. Isaías piensa en un Dios santo, transcendente, algo lejano, que está en el templo, pero habla también de él a partir de su piedad y misericordia. En el verso 16 afirma que, a veces, no quiere tener compasión ni misericordia del pueblo impenitente: "Por eso, de sus jóvenes no se apiadará el Señor, con sus huérfanos y viudas no tendrá misericordia, pues todos son impíos y malvados, y toda boca profiere majadería. Por todo ello la ira de Dios no se ha podido calmar y su mano sigue amenazante". Aquí, sub especie contrarii, aparecen la compasión y la misericordia como esenciales a Dios. Y acusa a Judá de que su conducta no permite a Dios ser Dios, actuar según su modo de ser.

\subsubsection{Miqueas}

Miqueas es también un profeta del sur y, aparentemente, menos apasionado que los del norte, pero también sabe utilizar el lenguaje del amor para hablar de Dios. Cuando el pueblo le pregunta qué deben hacer para ponerse en paz con él, si tienen que ofrecer holocaustos o sacrificios, el profeta les responde que saben de sobra lo que Dios espera y quiere de ellos. Lo dice así, en Miqueas 6, 8: "Se te ha declarado, hombre, lo que es bueno, lo que Yahveh de ti reclama: tan sólo practicar la justicia, amar con pasión y caminar humildemente con tu Dios". El profeta tiene clara conciencia de que la relación del ser humano con Dios está basada en caminar con él, practicando la justicia y amando con pasión.

El profeta termina su libro con una especie de salmo. Después de todas las denuncias y anuncios que ha hecho, le recuerda a Dios cuál es su estilo, como si a Dios se le hubiese olvidado. Es el último recurso que tiene para convencer a Dios a que se vuelque hacia el pueblo - recurso muy propio de los profetas. Veamos el texto en Miqueas 7, 18-19:

¿Qué Dios hay como tú, que quite la culpa y pase por alto el delito del Resto de tu heredad? No mantendrá su cólera por siempre pues se complace en el amor; volverá a compadecerse de nosotros, pisoteará nuestras culpas. ¡Tú arrojarás al fondo del mar todos nuestros pecados! Serás fiel con Jacob y misericordioso con Abraham, tal como juraste a nuestros padres desde antiguo.

cicnte de que la rclación de Judá con Yahvch cs de desamor y de que mereccria la destrucción. Sin embargo, acaba con la esperanza: Dios esperaba y sigue esperando honradez y justicia de su pucblo. 
Miqueas, pues, profeta de lenguaje siempre claro y algo duro, que nunca ahorra palabras fuertes contra Jerusalén, termina con este salmo en el que recuerda de forma sencilla y llena de sentimiento y de amor cómo es Dios. Y se lo recuerda al Dios mismo para convencerlo de que actúe tal como es.

Esto es lo que se puede decir de esta época de la monarquía. El pueblo ya se había sedentarizado totalmente y las cosas iban bien, aparentemente. El fin de la nación ni siquiera se vislumbraba. Era un tiempo de aparente calma, de euforia, de progreso. No faltaban, sin embargo, las incoherencias, los engaños, las inconsecuencias, las irresponsabilidades, los egoísmos, las corrupciones y las infidelidades. Para enfrentar esta situación, el mejor camino que encontraron los profetas es el de recordar de nuevo y continuamente al pueblo y ¡a Dios mismo!, cómo es él: un Dios tierno, misericordioso, compasivo, con un corazón que se conmueve cuando piensa que el mal viene sobre su pueblo. Los profetas comprenden también que la persona humana y el pueblo están retados a ser como Dios es.

\section{Los últimos años del reino de Judá (600 a. C.)}

En el período anterior al año 600 a. C., en el reino de Judá se habían dado momentos diversos: habían gobernado reyes buenos y menos buenos. Pero lo que está claro es que cada vez se había desfigurado más la imagen de Dios, a pesar de los esfuerzos de los profetas. Dos reyes, Manasés y Amón, pervirtieron la imagen de Dios y desfiguraron sus imágenes vivientes (parece que Manasés fue el que acabó con la vida del profeta Isaías). Además, estos reyes se pusieron, más o menos de buena gana, en manos de los imperios de la región, como Asiria, y en Jerusalén se generó un ambiente cultural semejante al de Nínive, la gran capital de aquel imperio. Proliferaron las costumbres paganas.

Entonces surgió el profeta Sofonías para devolver a Dios su verdadera imagen y combatir las modas y costumbres extranjeras - vestidos y bebidas-, pues con dichas modas entraba también la idolatría, lo cual era el auténtico problema. En lugar de Dios se introducían otros dioses: las costumbres extranjeras, la opresión, la injusticia, el orgullo y la autosuficiencia.

\subsection{Sofonías}

El profeta Sofonías intentó cambiar aquella situación y, en parte, lo consiguió. Se encontró con un rey muy joven (subió al trono porque su padre Amón fue asesinado), con ganas e ilusión de cambiar y reformar. El profeta tuvo una fuerte influencia en él y pensó que todavía era salvable la situación. En este contexto, Sofonías tiene palabras duras contra la idolatría, contra lo que no era propio de Israel. Una palabra muy significativa es la de Sofonías 3 , 17, en la que define a Dios en contradicción con lo que se respiraba en el país. Dice así: 
"Yahveh tu Dios está en medio de ti34, jun poderoso salvador! El exulta de gozo por ti, te renueva por su amor; danza por ti con gritos de júbilo".

Esta predicación produjo su efecto. Además, el joven Josías descubrió que Sofonías no hablaba sólo de una imagen de Dios. Esa nueva imagen -amor, alegría por el bien del pueblo - no sería auténtica si no iba unida a la imagen de una nueva sociedad. De hecho, toda la reforma de Josías se orientó a que la nueva imagen de Dios produjera una vida nueva, y así cambiase la sociedad. Eso aparece en el movimiento deuteronómico - recordemos que la primera edición del libro del Deuteronomio se redactó en aquel momento- que se preocupa, a la vez, por cambiar al máximo la imagen de Dios y por purificar al máximo las relaciones humanas y sociales, sobre todo con los más pobres. Josías captó perfectamente la imagen de Dios que el profeta Sofonías inculcaba. Y precisamente por el afán de deshacerse de las costumbres extranjeras y de instaurar un modo de vida de acuerdo a la nueva imagen de Dios, sus enemigos lo mataron. El fin, pues, fue trágico, pero la historia ha juzgado a este rey cómo el que entendió perfectamente lo que significa que Dios es el Dios que salva, que es amoroso, que da nueva vida.

Esto es lo que muestra con claridad un texto de Jeremías, en el cual el profeta contrapone la imagen de Dios que tiene Josías con la que después tendrá su hijo Joaquín I -y muestra también cómo de la imagen de Dios depende nuestra relación con los otros. El texto es una fuerte crítica de Jeremías contra Joaquín, poniéndolo como modelo a su padre quien sí entendió la verdadera imagen de Dios.

¡Ay del que edifica su casa sin justicia y sus pisos sin derecho! De su prójimo se sirve de balde y su trabajo no le paga. El que dice: "voy a edificarme una casa espaciosa y pisos ventilados", y le abre sus correspondientes ventanas; pone paneles de cedro y los pinta de rojo. ¿Serás acaso rey porque seas un apasionado del cedro? Tu padre, ¿no comía y bebía? Pero fue justo y equitativo, y todo le iba bien. Juzgó la causa del humillado y del pobre, y todo le iba bien. ¿No es esto conocerme? —oráculo de Yahveh-. Pero tus ojos y tu corazón no están más que a la ganancia injusta, al derramamiento de sangre inocente, a oprimir y atropellar. Por tanto, así dice Yahveh respecto a Joaquín, hijo de Josías, rey de Judá: no plañirán por él: “¡Ay hermano mío!, ¡ay hermana mía!”; no plañirán por él: “¡Ay Señor!, ¡ay su Majestad! El entierro de un borrico será el suyo: arrastrarlo y tirarlo fuera de las puertas de Jerusalén (Jer 22, 13-19).

34. Sofonías prescnta aquí una increible imagen de Dios: está en el interior del pueblo, a pesar de que éste se estaba dejando llevar por otros dioses. 


\subsection{Jeremías}

Este clima de reforma generó esperanza en los alrededores de Jerusalén: en los pequeños pueblitos que ya no dependían administrativamente de ella, pero que tenían una manera semejante de ver la realidad. Uno de esos pueblitos era el de Jeremías, Anatot. Jeremías busca la renovación de sus compatriotas para que redescubran cómo es Dios, pero su prédica la lleva a cabo en una situación algo difícil. En efecto, mientras en Jerusalén todavía se vivía un ambiente nacionalista, su propio pueblo dependía hacía tiempo del imperio asirio, de modo que la renovación que impulsaba Jeremías no podía ir unida a una renovación de tipo social y política. A pesar de todo, Jeremías intenta que su pueblo redescubra a Dios y cambien las relaciones entre sus habitantes. En este contexto hay que situar algunos textos importantes en torno al año 628 a. C. -los de su primera etapa-, recogidos en los capítulos 2 y 3, 30 y 31. En ellos, Jeremías Ilama a la renovación y para ello les recuerda cómo se han apartado de un amor auténtico y tomado el camino de un falso amor. Así aparece en Jeremías 2, 2-3:

Ve y grita a los oídos de Jerusalén: así dice Yahveh: de ti recuerdo tu cariño juvenil, el amor de tu noviazgo; aquel seguirme tú por el desierto, por la tierra no sembrada.35. Consagrado a Yahveh estaba Israel, primicias de su cosecha. "Quienquiera que lo coma, será reo; mal le sucederá" —oráculo de Yahveh36.

Este primer amor auténtico se ha convertido en un falso amor. El pueblo ha cambiado, y por esto, al final del capítulo, Dios se lamenta diciendo: “ ¿Han visto alguna vez que una joven olvidase sus joyas o la novia su traje de boda? Pues bien, mi pueblo se ha olvidado de mi desde hace ya mucho tiempo. ¡Cómo sabes encontrar el camino hacia tus amantes! Por esto te son también conocidos los caminos que van hacia el mal" (Jer 2, 32-33). Después sigue la llamada, la conversión y la oferta de reconciliación en Jeremías 3, 1-5. 19-23:

Supongamos que despide un marido a su mujer; ella se va de su lado y es de otro hombre: ¿podrá volver a él?37, ¿no sería como una tierra manchada? Pues bien, tú has fornicado con muchos compañeros, iy vas a volver a mí! —oráculo de Yahveh-. Alza los ojos a los calveros y mira: ¿en dónde no fuiste gozada? A la vera de los caminos te sentabas para ellos, como el árabe en el desierto, y manchaste la tierra con tus fornicaciones y malicia. Se

35. En cstos fragmentos, Jcremías se parece mucho a Oscas. Ambos ticnen una gran sensibilidad para el tema del amor y ven la relación con Dios como una auténtica rclación de amor.

36. El Señor ha tomado al pueblo de Israel como su propio pueblo. Lo ama tanto que no soportará que nadic le haga daño.

37. Según la ley, bastante machista por supuesto, estaba totalmente prohibido hacer tal cosa. 
suspendieron las lloviznas de otoño, y faltó lluvia tardía38; pero tú tenías rostro de mujer descarada, rehusaste avergonzarte. ¿Es que entonces mismo no me llamabas: "Padre mío; el amigo de mi juventud eres tú?; ¿tendrá rencor para siempre?, ¿lo guardará hasta el fin?"39. Ahí tienes cómo has hablado; las maldades que hiciste las has colmado...40. Yo había dicho: "Sí, te tendré como a un hijo y te daré una tierra espléndida, flor de las heredades de las naciones". Y añadí: "Padre me llamarán y de mi seguimiento no se volverán". Pues bien, como engaña una mujer a su compañero, así me ha engañado la casa de Israel, oráculo de Yahveh. Voces sobre los calveros se oían: rogativas llorosas de los hijos de Israel, porque torcieron su camino, olvidaron a su Dios Yahveh. "Vuelvan, hijos apóstatas; yo remediaré sus apostasías". "Aquí nos tienes de vuelta a ti, porque tú, Yahveh, eres nuestro Dios". ¡Luego eran mentira los altos, la barahúnda de los montes! ¡Luego por Yahveh, nuestro Dios, se salva Israel!

El profeta, para llamar a la conversión al pueblo le recuerda su amor primero, le recuerda cómo este amor se ha falseado y cómo, a pesar de todo, Dios continúa llamando a la conversión, o sea, al amor. Dios ha amado a su pueblo desde siempre y para siempre. Ahora siente que se le remueven las entrañas y se siente lleno de ternura hacia el pueblo cuando ve que no va por buen camino. Así lo dice Dios: "Con amor eterno te he amado: por eso he reservado gracia para ti" $(31,3)$. "¿Es un hijo tan caro para mí Efraím, o niño tan mimado, que tras haberme dado tanto que hablar, tenga que recordarlo todavía? Pues, en efecto, se han conmovido mis entrañas por él; ternura hacia él no ha de faltarme" $(31,20)$.

Este clima de esperanza, sin embargo, acabó con la muerte de Josías. Su hijo Joaquín I, vasallo de Egipto, destruyó muy pronto el movimiento de reforma de Josías. Persiguió todo lo que había sido renovación y fue llevando al pueblo hacia su destrucción. En esta situación, Jeremías captó muy bien la reacción de Dios: "Mis entrañas, mis entrañas!, ¡me duelen las telas del corazón, se me salta el corazón del pecho!... porque mi alma ha oído... el clamoreo del combate" (4, 19). El clima de esperanza desaparece y se puede prever un futuro no sólo incierto, sino de destrucción. Entonces, el profeta se mete en la piel de Dios, descubre lo que Dios está pensando y siente cómo se le revuelven las entrañas por el desastre del pueblo.

En esos momentos, en que parece como si Dios estuviera ya cansado de ver su amor no correspondido, Dios parece chantajear a su pueblo a través de Jere-

38. Es una concepción profética muy interesante, la de que el pecado y la infidelidad humana tienen un efecto negativo sobre la misma naturaleza: la puede malear.

39. Denuncia el intento por esconder las maldades con palabras bonitas.

40. Desde el verso 5 se debe pasar al 19 —n medio hay una especie de actualizaciónpara que el texto tenga coherencia. 
mías: si continúan así no le dejan actuar con piedad, con compasión, con ternura y con misericordia, y en consecuencia, todo les irá mal. Lo significativo es que por la infidelidad de su pueblo, Dios no podrá actuar tal como es: misericordioso. En este contexto se sitúa Jeremías 13, 14, en el momento en que Dios ha mandado al profeta que compre un ceñidor de lino -material que era propio de los sacerdotes 41 - y que lo esconda en un lugar seco. El texto narra a continuación que, cuando tiempo después el profeta va recoger el ceñidor, se encuentra con que éste ya se ha estropeado y no sirve para nada. El trasfondo es el tema del templo. El templo nuevo de la reforma de Josías que se ha convertido en algo totalmente inútil y no sirve para nada, pues no permite que Dios actúe como él es. Dice Yahveh: "y los estrellaré, a cada cual contra su hermano, padres e hijos a una, sin que piedad, compasión y lástima me quiten de destruirlos".

También Jeremías 16, 5 presenta a un Dios que parece estar ya cansado y no quiere actuar con misericordia. Manda entonces al profeta que haga un nuevo acto simbólico. Le dice: "No entres en casa de duelo, ni vayas a plañir, ni los consueles; pues he retirado mi paz de este pueblo, la merced y la compasión". Cosa difícil de cumplir, pues en aquella cultura, dejar de hacer duelo por un difunto, era algo considerado muy inhumano. Se vuelve a repetir que Dios no quiere actuar con compasión y con paz con su pueblo. Por esta razón no está permitido hacer duelo por un pueblo que está a punto de morir o que, de hecho, ya está muerto.

Con estos actos simbólicos, Jeremías pretende que el pueblo reaccione, que reconozca honradamente su situación y que pida lo único que puede pedir: que Dios sea fiel a su nombre, que sea fiel a lo que él es. Esta es la expresión que encontramos en Jeremías 14, 7.21, donde el pueblo reconoce que las culpas lo acusan, que sus infidelidades son muchas, que ha pecado contra Dios, y le pide al Señor que actúe por amor a su nombre, que no desprecie a su pueblo, que no deshonre el trono de su gloria, que se acuerde de su alianza y no la anule.

En esta realidad del pueblo que, habiendo vivido la gran experiencia fundante de liberación, va siendo destruido, lo que está en juego es precisamente, el nombre de Dios. Y ¿cuál es el nombre de Dios? Quizás pueda decirse que Dios nunca había definido su nombre, pero cuando le habían preguntado por dicho nombre había respondido aquel que siempre estará con ellos. Por esa razón, lo que está ocurriendo, la destrucción que está viviendo el pueblo con el rey Joaquín I, pone en cuestión el nombre de Dios, y por eso sale tantas veces en el texto la expresión por amor de tu nombre referida a Dios. Esto significa que Dios, actuando contra la destrucción del pueblo, conseguirá que vuelva a sobresalir su nombre, que Dios vuelva a ser reconocido tal como es.

41. El pueblo había puesto grandes esperanzas en el templo y el mismo rey Joaquín I se scrvia de ćstas para podcr manipular a aquél. 


\subsection{Habacuc y el final de Jeremías}

Esto que aparece en ese momento de la vida de Jeremías aparece también en un profeta contemporáneo: Habacuc. En un breve libro, este profeta dice lo mismo que Jeremías, no porque se hayan puesto de acuerdo, sino porque han vivido la misma realidad. Así leemos en Habacuc 3, 2: "¡Yahveh, he oído tu nombre, tu obra venero, Yahveh! ¡Hazlo revivir... dalo a conocer, aun en la ira acuérdate de tener compasión!". Para Habacuc la mejor traducción del nombre Yahveh es que, en medio de la ira42, se acuerda de tener compasión. Estos son dos intentos proféticos de hacer comprender al pueblo que, si realmente no permiten a Dios ser quien es, lo pasará muy mal. Con todo, a pesar de esta llamada a la conversión, el pueblo de Judá no se convierte y cada vez más va tomando un camino que lo lleva a la ruina.

Jeremías prevee esta inminente caída y destrucción a manos de los enemigos. Es interesante que, sin embargo, cuando Jeremías cae en la cuenta de la gravedad de la situación y de la imposibilidad de solución, estando en la prisión comienza a hablar del futuro y comienza a escuchar la voz alegre y gozosa, la voz del novio y de la novia. Vuelve a utilizar el lenguaje del amor para hablar de la relación entre Dios y el pueblo: voz de quienes traen sacrificios de alabanza al templo y dicen "alaben al señor porque es bueno, porque su amor es eterno". Jeremías por lo tanto, en el momento en que la imagen de Dios está siendo destruida totalmente por la actitud del pueblo — no le deja actuar con bondad, con compasión, con ternura y con amor- presenta de nuevo la figura de un Dios que es bueno y cuyo amor no termina nunca. $Y$ esto, en un momento en que no parece haber futuro alguno.

Y lo mismo hará cuando, poco después, por miedo a Nabucodonosor, sus compatriotas quieren huir a Egipto. Jeremías vuelve a hablar de un Dios compasivo y es capaz incluso de mover a compasión al mismo Nabucodonosor. En conclusión, el mensaje de Jeremías es muy amplio, pero para hablar de Dios esta es la imagen que utiliza: la del matrimonio, la de la relación de amor... Y esto, en momentos difíciles.

\subsection{Ezequiel}

El profeta Ezequiel fue uno de los primeros deportados a Babilonia cuando Jerusalén cayó por primera vez en manos de Nabucodonosor. En esta primera deportación fueron exiliados un grupo de personas que Nabucodonosor consideraba que le podía traer problemas, una de ellas fue el sacerdote Ezequiel. En el exilio, este profeta desempeñó un papel parecido al de Jeremías en la tierra de Judá, a punto de ser destruida. Intentó que el exilio no se convirtiese en definiti-

42. De hecho, hay motivos más que suficientes para el enfado y el furor de Yahveh contra su pucblo. Sería normal, por lo tanto, que sofocase su compasión y su ternura. 
vo. Al principio todavía existía esperanza, porque Jerusalén y su templo seguían en pie. Pero Ezequiel constata el doble peligro que corría el pueblo en el exilio: o creer en una salvación mágica o caer en el derrotismo y en la desesperación.

Ante esto, Ezequiel se dedica a proponer de nuevo la auténtica imagen de Dios que se estaba perdiendo, lo cual lleva a cabo en cinco pasos: (1) constata la infidelidad del pueblo de Dios que se enamora continuamente de otros pueblos; (2) quiere que el pueblo se enamore de nuevo y en serio de Yahveh; (3) contrasta la superficialidad del pueblo en su relación con la constancia y la profundidad de la relación de Dios; (4) presenta al Dios que amenaza; (5) muestra al Dios que, en último término se vuelve a compadecer de su pueblo.

En el capítulo 23 denuncia con claridad la infidelidad del pueblo, su enamoramiento continuo de otros dioses. He aquí el texto (vv. 5. 7.9.12. 14-17.19-20):

Oholá [Israel] se prostituyó cuando me pertenecía a mí; se enamoró perdidamente de sus amantes, los asirios sus vecinos... Les otorgó sus favores eran todos ellos la flor de los asirios-y, con todos aquellos de los que se había enamorado, se contaminó al contacto de todas sus basuras... Por eso yo la entregué en manos de sus amantes, en manos de los asirios de los que se había enamorado... Su hermana Oholibá vio esto... Se enamoró de los asirios, gobernadores y prefectos, vecinos suyos, magníficamente vestidos, hábiles caballeros, y todos ellos jóvenes apuestos... vio hombres pintados en la pared... que representaban a los babilonios,... y en cuanto los vio se enamoró de ellos y les envió mensajeros a Caldea. Los babilonios vinieron donde ella, a compartir el lecho de los amores y a contaminarla con su lascivia; y cuando se contaminó con ellos, se aburrió de ellos... multiplicó sus prostituciones, acordándose de... cuando se prostituía en el país de Egipto, y se enamoraba de aquellos disolutos de carne de asnos y miembros de caballos.

En perspectiva histórica Ezequiel pasa revista a todos los pueblos a los que se entregó el pueblo de Dios. La infidelidad de Israel consiste en haberse enamorado continuamente de otros pueblos.

Después intenta conseguir que el pueblo se vuelva a enamorar de Dios, aunque el profeta es consciente de su superficialidad y de sus muchas palabras, que no acaban de convertirse en realidad. Así lo constata en Ezequiel 33, 31-32:

$\mathrm{Y}$ vienen a ti en masa, y mi pueblo se sienta delante de ti; escuchan tus palabras, pero no las ponen en práctica. Porque te prometen amor con su boca, pero su corazón sólo anda buscando su interés. Tú eres para ellos como una canción de amor, graciosamente cantada, con acompañamiento de buena música. Escuchan tus palabras, pero no hay quien las cumpla.

Ezequiel llama aquí nuevamente al amor del pueblo, consciente de que Dios conoce la reacción del pueblo de Israel, totalmente superficial, propia de quien no se acaba de convertir y no acaba de amar a Dios. 
La superficialidad del pueblo en su relación con Dios contrasta con la manera profunda y fiel de relacionarse Dios con su pueblo, Dios no se merece la respuesta del pueblo, idea que se encuentra en muchos capítulos de Ezequiel, y más concretamente en $16,5,8.45$ y en $20,17.40 .41$ :

Ningún ojo se apiadó de ti para brindarte alguno de estos menesteres, por compasión a ti. Quedaste expuesta en pleno campo, porque dabas repugnancia, el día en que viniste al mundo... Entonces pasé yo junto a ti y te vi. Era tu tiempo, el tiempo de los amores. Extendí sobre ti el borde de mi manto43 y cubrí tu desnudez; me comprometí con juramento, hice alianza contigo —oráculo del señor Yahvehy tú fuiste mía... Hija eres, sí, de tu madre, que dejó de amar a su marido y a sus hijos...

Pero tuve una mirada de piedad para no exterminarlos [a los hijos de Israel], y no acabé con ellos en el desierto... Será en mi santa montaña... donde me servirá toda la casa de Israel, toda ella en esta tierra. Allí los acogeré amorosamente... Como calmante aroma yo los acogeré amorosamente cuando les haya hecho salir de entre los pueblos y les reúna de en medio de los países en los que ustedes han sido dispersados; y por ustedes me mostraré santo a los ojos de las naciones.

En consecuencia, Dios amenaza con no mirar ya al pueblo con compasión, como aparece en Ezequiel 5, 11; 7, 4.9; 8, 18; 9, 5.10; 24,14:

Por eso, por mi vida... que de la misma manera que tú has contaminado mi santuario... yo también te rechazaré a ti sin una mirada de piedad; tampoco yo te perdonaré... No tendré para ti una mirada de piedad, no te perdonaré, sino que te pediré cuentas de tu conducta... No tendré una mirada de piedad, no perdonaré; te pediré cuentas... Pues yo también he de obrar con furor; no tendré una mirada de piedad, no perdonaré. Con voz fuerte gritarán a mis oídos, pero yo no les escucharé... $\mathrm{Y}$ a los otros oí que les dijo: "recorran la ciudad detrás de él y hieran. No tengan una mirada de piedad, no perdonen... mátenlos hasta que no quede uno...". Pues bien, tampoco yo tendré una mirada de piedad ni perdonaré. Haré caer su conducta sobre su cabeza... Yo, Yahveh, he hablado, y cumplo las palabras: no me retractaré.

Al final, sin embargo, y a pesar de todo, Dios promete nuevamente mostrar su compasión. Así lo dice en Ezequiel 39, 25: "Ahora voy a hacer volver a los cautivos de Jacob, me compadeceré de toda la casa de Israel, y me mostraré celoso de mi santo nombre".

(Continuará.)

43. Era la manera que tenían en aquel tiempo y cultura de ofrecer y mostrar cl deseo de tener una relación seria de amor. 